\title{
PELATIHAN DAN PENDAMPINGAN PENYUSUNAN PROPOSAL PENELITIAN TINDAKAN KELAS (PTK) DI SDN SAMBIGEDE 03
}

\author{
Prihatin Sulistyowati ${ }^{1)}$, Arnelia Dwi Yasa $^{2}$ \\ ${ }^{1)}$ Program Studi PGSD, Universitas Kanjuruhan Malang \\ Email: prihatinsulistyowati@unikama.ac.id \\ 2)Program Studi PGSD, Universitas Kanjuruhan Malang \\ Email: arnelia@unikama.ac.id
}

\begin{abstract}
Professional teachers should have basic science and technology, practical methodologies, always trying to hone competence through training and lifelong learning, reading a book, and research activities. Teachers are required to implement PTK to improve the professionalism of teachers. This dedication aims to enhance the understanding and skills of SDN Sambigide 03 teachers in preparing proposals and conducting Classroom Action Research through training and mentoring programs for TKs in schools. Based on the results of dedication can be concluded that the devotion done in SDN Sambigede 03 has been running well. The activity starts with pretest, then submission of Class Action Research material with lecture method, discussion, the practice of making Class Action Research proposal (PTK) and ending with post-test. The results showed that there was an increase in the participants' understanding of the making of Class Action Research proposal (PTK) by 19.46\%. There is a difference in the mastery of the concept of PTK before and after training and mentoring. Eight teachers got an average score, and seven teachers got high scores for knowledge of the idea. Thus, it can be said that the training and mentoring activities of the PTK proposal submission are said to be successful because of the N-Gain score in the medium and high category.
\end{abstract}

Keywords: Proposal PTK, SDN Sambigide 03

\section{PENDAHULUAN}

Guru yang profesional harus memiliki dasar ilmu pengetahuan dan teknologi, metodologi yang efektif, selalu berusaha mengasah kompetensi melalui pelatihan dan kemauan belajar seumur hidup, kegemaran membaca buku, serta kegiatan penelitian peningkatan pembelajaran di kelas.

Sudiana (2013:1) menyatakan bahwa dalam rangka pengembangan profesional, guru tidak bisa melepaskan dirinya dari kegiatan akademik penelitian. Dalamkegiatan akademik penelitian, guru memiliki peran strategis dalam pengembangan kompetensi professional sekaligus sebagai upaya dalam meningkatkan dan memperbaiki proses maupun hasil belajar siswa. Penelitian yang berfokus pada perbaikan kualitas praktek pembelajaran sering diistilahkan dengan penelitian tindakan kelas (PTK). Untuk meningkatkan mutu pembelajaran guru wajib melaksanakan penelitian tindakan kelas.

PTK bertujuan meningkatkan kinerja guru dan hasil belajar siswa, bukan saja mengungkapkan penyebab berbagai permasalahan yang dihadapi dalam pembelajaran Suwandi (2007: 13). Kegiatankegiatan tersebut mutlak dimiliki guru profesional sesuai tuntutan guru di era globalisasi. Saat ini penelitian tindakan kelas 
(PTK) memang mendapatkan perhatian yang cukup besar dalam dunia pendidikan. Ada banyak hal yang menjadi alasan diantaranya bahwa, hasil-hasil dari PTK dapat langsung dimanfaatkan untuk meningkatkan atau memperbaiki kualitas pembelajaran di dalam kelas. Selain itu, laporan PTK juga sangat bermanfaat bagi guru yang bersangkutan dalam hal kenaikan pangkat dan kredit pengembangan profesi keguruan. Kegiatan meneliti, khususnya PTK menjadi prasyarat dalam kenaikan pangkat guru. Dengan demikian, kegiatan meneliti maupun menulis, mau tidak mau, suka tidak suka, harus dilakukan oleh guru. Untuk keperluan peningkatan profesi guru di SDN Sambigede 03, mereka membutuhkan kegiatan pelatihan dan pendampingan PTK, agar mereka memiliki pengetahuan dan ketrampilan pembuatan PTK di sekolah.

\section{METODE PELAKSANAAN}

Metode pelatiahan dan pendampingan penyunsunan PTK dilakukan melalui tiga cara yaitu metode ceramah, diskusi dan latihan praktek (drill practice) pembuatan proposal penelitian. Metode ceramah ini dilaksanakan karena guru SDN Sambigede 03 mengalami kesulitan dalam pembuatan proposal PTK. Kegiatan pelatihan ini mempergunakan tayangan laptop dan LCD untuk menjelaskan materi PTK. Materi PTK yang dipaparkan yakni tentang cara pembuatan (latar belakang masalah, perumusan masalah, tujuan dan manfaat penelitian, kajian pustaka, metode penelitian). Dalam kegiatan pelatihan ini juga diberikan hand out agar memudahkan peserta dalam memahami materi. Pemberian materi dilakukan dua sesi yakni materi pertama tentang PTK dan materi dua tentang cara menyunsun PTK. Pemberian materi selama dua jam.

Sesi diskusi dilakukan setelah penyampaian materi tentang PTK. Pada sesi ini, guru diberikan kesempatan untuk menyampaiakan permasalahanpermasalahan yang dihadapi oleh guru selama mengajar di kelas. Sehingga guru akan mengetahui keputusan yang akan diambil untuk menyelasaikan permasalahan yang terjadi di dalam kelasnya.

Metode latihan praktek (drill practice) dilaksanakan setelah pelaksanaan diskusi. Guru-guru diminta untuk membuat proposal penelitian yang meliputi penyusunan latar belakang masalah, perumusan masalah, tujuan penelitian, manfaat penelitian, kajian pustaka dan metode penelitian. Praktek penyunsunan panduan proposal PTK dilakukan selama dua jam, untuk review satu jam. Pada praktek pembuat rangcangan proposal PTK. Guru-guru diminta untuk mengisi panduan penulisan proposal yang telah disediakan oleh Tim pengabdi.

Bentuk evaluasi yang digunakan adalah Pre Test dan Post Test serta mereview proposalhasil kerja mitra selama mengikuti pelatihan. Indikator yang digunakan adalah materi yang diberikan selama pelatihan yang terdiri dari: (1) latar belakang masalah, (2) perumusan masalah, (3) tujuan penelitian, (3) manfaat penelitian, (4) landasan teori dan (5) metode penelitian. Setiap jawaban diberi skor berdasarkan hasil review proposal seperti tabel 1 .

Tabel 1. Skor review proposal peserta

\begin{tabular}{|c|c|c|c|c|}
\hline \multirow{2}{*}{ Indikator } & \multicolumn{4}{|c|}{ Skor } \\
\hline & 4 & 3 & 2 & 1 \\
\hline \multicolumn{5}{|c|}{ Latar Belakang Masalah } \\
\hline \multicolumn{5}{|l|}{ Perumusan Masalah } \\
\hline \multicolumn{5}{|l|}{ Tujuan Penelitian } \\
\hline \multicolumn{5}{|l|}{ Manfaat Penelitian } \\
\hline \multicolumn{5}{|l|}{ Kajian Pustaka } \\
\hline Metode Penelitian & & & & \\
\hline
\end{tabular}

\section{Penilaian :}

4 = Baik sekali

$3=$ Baik

$2=$ Sedang

$1=$ Kurang

$$
P=\frac{f}{N} X 100 \%
$$

Keterangan :

$\mathrm{P} \quad=$ persentase yang dicari 
$\mathrm{F} \quad=$ frekuensi yang muncul

$\mathrm{N} \quad=$ total frekuensi

(Winarsunu,2009:20)

Keberhasilan :

jika skor review mencapai $75 \%$

Untuk mengetahui pengaruh pemberian pelatihan dan pendampingan terhadap penguasaan materi PTK, dilakukan analisis deskriptif kualitatif beruapa analisis N-Gain Score (Hake, 1999) dengan rumus sebagai berikut :

$$
(g)=\frac{S_{\text {post }}-S_{\text {pre }}}{S_{\text {mak }}-S_{\text {pre }}}
$$

Keterangan :

(g) = nilai gain

Spost $=$ nilai post-test

Spre = nilai pre-test

Smax $=$ nilai maksimal

Gain menunjukkan perbedaan penguasaan konsep tentang PTK sebelum dan setelah diberikan perlakuan. Gain skor ternomalisasi menunjukkan tingkat efektivitas perlakuan dari pada perolehan skor atau post test. Nilai (g) yang diperoleh diinterpretasikan dengan klasifikasi pada Tabel 3.2.

$$
(g)=\frac{S_{\text {post }}-S_{\text {pre }}}{S_{\text {mak }}-S_{\text {pre }}}
$$

Tabel 2. Interpretasi Nilai Gain yang Dinormalisasi

\begin{tabular}{cc}
\hline Nilai (g) & Interpretasi \\
\hline$(\mathrm{g}) \geq 0,7$ & Tinggi \\
$0,7>(\mathrm{g}) \geq 0,3$ & Sedang \\
$(\mathrm{g})<0,3$ & Rendah \\
\hline
\end{tabular}

\section{HASIL DAN PEMBAHASAN}

Sebelum kegiatan Pelatihan dan Pendampingan Penyunsunan Proposal Penelitian Tindakan Kelas (PTK) di SDN Sambigede 03 perlu dilaksanakan adanya persiapan berikut :

1. Mengadakan konsultasi dengan kepala SDN Sambigede 03 Malang, minta ijin pelaksanaan pelatihan dan pendampingan penyunsunan proposal Penelitian Tindakan Kelas (PTK) di SDN Sambigede 03.

2. Melakukan koordinasi dengan kepala SDN Sambigede 03 mengenai tempat, waktu dan jumlah peserta sebagai persiapan pelaksanaan pelatihan dan pendampingan.

3. Melakukan koordinasi dengan kepala SDN Sambigede 03 Malang mengenai susunan acara pelatihan dan pendampingan penyunsunan proposal Penelitian Tindakan Kelas (PTK) di SDN Sambigede 03.

4. Mempersipakan materi kegiatan, khususnya materi PTK.

Setelah persiapan selesai, ditetapkan waktu kegiatan pada hari Jumat dan Sabtu tanggal 29 s.d 30 Juli 2016 pukul 12.00-15.00 di ruang kelas 2 SDN Sambigede 03 Malang.

Pelatihan dan pendampingan penyunsunan proposal Penelitian Tindakan Kelas (PTK) ini diikuti oleh guru SDN Sambigede 03 Malang yang terdiri dari 15 orang yakni kepala sekolah, guru kelas, guru agama, guru olahraga. Respon guru terhadap pelaksanaan kegiatan ini, mereka merasa senang karena dapat menambah informasi dan pengetahuan tentang PTK selain itu juga dapat sharing apabila terdapat permasalahan yang terjadi di kelas sehingga dapat menemukan solusi atas permasalahan yang dihadapinya. Kepala sekolah juga memberikan respon positif atas terselenggaranya kegiatan ini, karena selama ini guru SDN Sambigede 03 mengalami kesulitan dalam penyunsunan PTK. Dengan adanya kegiatan ini, guruguru mengetahui bahwa penyunsunan PTK itu mudah dan mereka menjadi termotivasi untuk membuat PTK.

Kegiatan pengabdian kepada masyarakat ini dilaksanakan dengan perincian sebagai berikut :

1. Kehadiran dan tingkat partisipasi peserta melalui presensi kehadiran adalah $100 \%$. 
2. Berdasarkan jadwal pelaksanaan, serta ketepatan waktu pelaksaan, kegiatan pengabdian ini telah terlaksana dengan baik, sesuai yang di rencanakan.

3. Pada akhir acara ini para peserta memperoleh wawasan tentang PTK.

Kegiatan pelatihan dan pendampingan ini dilakukan dengan tiga cara yakni :

1. Metode ceramah, tim pengabdi menggunakan metode ceramah dengan bantuan media laptop dan LCD. Menjelaskan materi proposal PTK secara rinci yang meliputi: pengertian PTK, cara membuat (latar belakang masalah, perumusan masalah, tujuan dan manfaat penelitian, landasan teoretis, metode penelitian).

2. Metode Diskusi, tim pengabdi memberikan kesempatan kepada guru-guru untuk menyampaiakan permasalahan-permasalahan yang dihadapi oleh guru selama mengajar di kelas. Sehingga, tim pengabdi dan guru dapat mendiskusikan solusi atas permasalahan yang dihadapi.

3. Latihan Praktek (drill practice), setelah diskusi selesai, untuk pendalaman materi sekaligus mengaplikasikan antara teori dengan kenyataan, guru-guru diminta untuk mengisi panduan penulisan proposal yang telah disediakan oleh Tim pengabdi.

Bentuk evaluasi yang digunakan pada pelatihan dan pendampingan PTK, berupa nilai proposal hasil kerja mitra. Nilai yang didapatkan ada dua jenis penilaian yakni nilai pretes dan nilai post test.

Pengisian panduan penulisan proposal PTK secara keseluruhan mendapatkan prosentase skor sebesar $64,17 \%$ sedangkan batas skor keberhasilan 75\%. Hasil dari prosentase pre test dapat disimpulkan bahwa pengisian panduan penulisan proposal belum mencapai skor yang ditentukan yakni $75 \%$.
Tabel 3. Nilai Pre Test Pengisian Panduan Proposal

\begin{tabular}{|c|c|c|c|c|c|c|c|c|}
\hline \multirow{2}{*}{ No } & \multirow{2}{*}{$\begin{array}{l}\text { Nama } \\
\text { Guru }\end{array}$} & \multicolumn{6}{|c|}{ Skor Indikator } & \multirow[t]{2}{*}{$\begin{array}{c}\text { JML } \\
\text { SKOR }\end{array}$} \\
\hline & & 1 & 2 & 3 & 4 & 5 & 6 & \\
\hline 1 & A & 4 & 4 & 3 & 4 & 3 & 3 & 21 \\
\hline 2 & B & 3 & 2 & 2 & 3 & 2 & 3 & 15 \\
\hline 3 & $\mathrm{C}$ & 3 & 4 & 4 & 4 & 4 & 4 & 23 \\
\hline 4 & $\mathrm{D}$ & 3 & 3 & 4 & 2 & 3 & 4 & 19 \\
\hline 5 & $\mathrm{E}$ & 4 & 4 & 4 & 3 & 3 & 4 & 22 \\
\hline 6 & $\mathrm{~F}$ & 4 & 4 & 3 & 3 & 2 & 3 & 19 \\
\hline 7 & G & 3 & 3 & 4 & 4 & 4 & 4 & 22 \\
\hline 8 & $\mathrm{H}$ & 4 & 4 & 3 & 4 & 2 & 3 & 20 \\
\hline 9 & I & 3 & 2 & 4 & 4 & 3 & 3 & 19 \\
\hline 10 & $\mathrm{~J}$ & 4 & 4 & 4 & 3 & 3 & 4 & 22 \\
\hline 11 & K & 4 & 3 & 4 & 3 & 4 & 3 & 21 \\
\hline 12 & $\mathrm{~L}$ & 3 & 2 & 2 & 4 & 3 & 4 & 18 \\
\hline 13 & M & 3 & 3 & 4 & 2 & 4 & 3 & 19 \\
\hline 14 & $\mathrm{~N}$ & 4 & 3 & 3 & 2 & 3 & 4 & 19 \\
\hline 15 & $\mathrm{O}$ & 4 & 3 & 4 & 4 & 3 & 4 & 22 \\
\hline \multicolumn{2}{|c|}{ Rata-Rata } & 3,5 & 3,2 & 3,5 & 3,3 & 3,1 & 3,5 & \\
\hline \multicolumn{8}{|c|}{ Prosentase } & $83,63 \%$ \\
\hline
\end{tabular}

Tabel 4. Nilai Post Test Pengisian Panduan Proposal

\begin{tabular}{|c|c|c|c|c|c|c|c|c|}
\hline \multirow{2}{*}{ No } & \multirow{2}{*}{$\begin{array}{l}\text { Nama } \\
\text { Guru }\end{array}$} & \multicolumn{6}{|c|}{ Skor Indikator } & \multirow{2}{*}{$\begin{array}{c}\text { JML } \\
\text { SKOR }\end{array}$} \\
\hline & & 1 & 2 & 3 & 4 & 5 & 6 & \\
\hline 1 & A & 3 & 3 & 2 & 2 & 2 & 3 & 15 \\
\hline 2 & B & 1 & 1 & 1 & 2 & 2 & 2 & 9 \\
\hline 3 & $\mathrm{C}$ & 2 & 1 & 1 & 2 & 2 & 2 & 10 \\
\hline 4 & $\mathrm{D}$ & 1 & 2 & 1 & 2 & 2 & 2 & 10 \\
\hline 5 & E & 1 & 1 & 2 & 2 & 2 & 2 & 10 \\
\hline 6 & $\mathrm{~F}$ & 2 & 1 & 2 & 1 & 2 & 2 & 10 \\
\hline 7 & $\mathrm{G}$ & 1 & 1 & 2 & 2 & 2 & 2 & 10 \\
\hline 8 & $\mathrm{H}$ & 1 & 2 & 2 & 2 & 2 & 2 & 11 \\
\hline 9 & I & 2 & 2 & 2 & 2 & 2 & 2 & 12 \\
\hline 10 & $\mathrm{~J}$ & 1 & 1 & 2 & 2 & 2 & 2 & 10 \\
\hline 11 & K & 2 & 1 & 2 & 2 & 2 & 2 & 11 \\
\hline 12 & $\mathrm{~L}$ & 1 & 1 & 2 & 1 & 2 & 2 & 9 \\
\hline 13 & M & 1 & 1 & 2 & 2 & 2 & 3 & 11 \\
\hline 14 & $\mathrm{~N}$ & 1 & 1 & 2 & 2 & 2 & 2 & 10 \\
\hline 15 & $\mathrm{O}$ & 1 & 1 & 2 & 2 & 2 & 1 & 9 \\
\hline \multicolumn{2}{|c|}{ Rata-Rata } & 1,4 & 1,3 & 1,8 & 1,9 & 2 & 2,1 & \\
\hline \multicolumn{8}{|c|}{ Prosentase } & $43,6 \%$ \\
\hline
\end{tabular}


Keterangan:

1 = latar belakang masalah

$2=$ perumusan masalah

$3=$ tujuan penelitian

$4=$ manfaat penelitian

$5=$ kajian pustaka

$6=$ metode penelitian

Pengisian panduan penulisan proposal PTK secara keseluruhan mendapatkan prosentase skor sebesar $83,63 \%$ sedangkan batas skor keberhasilan 75\%, prosentase post test dapat disimpulkan bahwa pengisian panduan penulisan proposal sudah mencapai skor yang ditentukan. Nilai pre test dan post test hasil kegiatan pelatihan dan pendampingan menunjukkan bahwa terjadi peningkatan pemahaman peserta tentang pembuatan proposal PTK sebesar 19,46\% sehingga dapat dikatakan pelatihan dan pendampingan penyunsunan proposal PTK dikatakan berhasil.

Pengaruh pemberian pelatihan dan pendampingan terhadap Penguasaan materi PTK, dilakukan analisis deskriptif kualitatif beruapa analisis N-Gain Score. Hasil analisis N-Gain Score dapat dilihat pada Tabel 5.

Tabel 5. Penguasaan Konsep tentang PTK

\begin{tabular}{cccccc}
\hline No & Guru & $\begin{array}{c}\text { Pre } \\
\text { Test }\end{array}$ & $\begin{array}{c}\text { Post } \\
\text { Test }\end{array}$ & $\begin{array}{c}\text { N-Gain } \\
\text { Score }\end{array}$ & Kategori \\
\hline 1 & A & 15 & 21 & 0,7 & Tinggi \\
2 & B & 9 & 15 & 0,4 & Sedang \\
3 & C & 10 & 23 & 0,6 & Sedang \\
4 & D & 10 & 19 & 0,9 & Tinggi \\
5 & E & 10 & 22 & 0,9 & Tinggi \\
6 & F & 10 & 19 & 0,6 & Sedang \\
7 & G & 10 & 22 & 0,9 & Tinggi \\
8 & H & 11 & 20 & 0,7 & Tinggi \\
9 & I & 12 & 19 & 0,6 & Sedang \\
10 & J & 10 & 22 & 0,9 & Tinggi \\
11 & K & 11 & 21 & 0,8 & Tinggi \\
12 & L & 9 & 18 & 0,6 & Sedang \\
13 & M & 11 & 19 & 0,6 & Sedang \\
14 & N & 10 & 19 & 0,6 & Sedang \\
15 & O & 9 & 22 & 0,8 & Tinggi \\
\hline
\end{tabular}

Berdasarkan Tabel 5 menunjukkan bahwa terdapat perbedaan penguasaan konsep tentang PTK sebelum dan setelah diberikan perlakuan. Ada delapan guru yang memperoleh skor sedang untuk penguasaan konsepnya dan tujuh guru mendapat skor tinggi untuk penguasaan konsepnya. Sehingga, dapat dikatakan kegiatan pelatihan dan pendampingan penyunsunan proposal PTK dikatakan berhasil karena nilai N-Gain skor dalam kategori sedang dan tinggi.

\section{KESIMPULAN}

Pengabdian yang dilakukan untuk guru SDN Sambigede 03 Malang telah berjalan dengan baik. Rangkaian kegiatan mulai dari pre test, pemberian materi PTK tentang cara pembuatan (latar belakang masalah, perumusan masalah, tujuan dan manfaat penelitian, landasan teoretis, metode penelitian) dengan metode ceramah. Pada, sesi diskusi, guru diberikan kesempatan untuk menyampaikan permasalahan-permasalahan yang dihadapi oleh guru selama mengajar di kelas. Dilanjutkan dengan latihan praktek, guru diminta untuk membuat outline penelitian yang nantinya akan dikembangkan dalam bentuk proposal berupa penyusunan latar belakang masalah, perumusan masalah, tujuan penelitian, manfaat penelitian, landasan teori dan metode penelitian.

Pelatihan dan pendampingan penyunsunan proposal PTK telah berjalan sesuai dengan apa yang direncanakan. Hasil dari Kegiatan pengabdian ini memberikan banyak manfaat bagi guru, kepala sekolah dan pemateri. Kegiatan pengabdian ini semata-mata dilakukan untuk meningkatkan kemampuan guru dalam menyunsun PTK dalam upaya memperbaiki kualitas pembelajaran di kelas. 


\section{DAFTAR PUSTAKA}

Bambang, Dwiloka. 2005. Teknik Menulis Karya Ilmiah. Jakarta: Rineka Cipta.

Elfindri. 2006. Cara Cerdas Mendapatkan Dana Riset. Cibubur: Visimedia.

Hake, R. R. 1999. American Educational Research Association's Division D. Measurement and Research Methodology: Analyzing Change/ Gain Scores. USA: Woodland.

H.A.R. Tilaar. 2008. Manajemen Pendidikan Nasional. Bandung: Rosdakarya.

Rochiati Wiriaatmaja. 2005. Metode Penelitian Tindakan Kelas. Bandung: Rosdakarya.

Sarwiji Suwandi. 2007. Penelitian Tindakan Kelas. Surakarta: Panitia Sertifikasi.

Suandi, I Nengah, dkk. 2008. Peningkatan Keterampilan Menulis Karya Ilmiah

Melalui Teknik Analisis Pemodelan pada Siswa SMA Negeri1 Singaraja (Laporan Penelitian).

Sudiana, I Nyoman. 2013. Penelitian Tindakan Kelas makalah disampaikan dalam

Pelatihan Penyusunan Proposal Tindakan Kelas bagi Guru-Guru Bahasa Indonesia pada Tanggal 8 Juli 2013 di SMAN 2 Semarapura.

Sutama, I Made. 2003. Pendahuluan Artikel Ilmiah dalam Jurnal

MediaKomunikasi FPIPS IKIP Negeri Singaraja (Laporan Penelitin).

Tarigan, Henry Guntur. (1994). Menulis sebagai Suatu Keterampilan Berbahasa.

Angkasa: Bandung.

UU Guru dan Dosen. 2010. UU RI No. 14 Tahun 2005. Jakarta: Sinar Grafika.

Winarsunu, T. 2009. Statistik dalam Penelitian Psikologi dan Pendidikan. Malang : UMM Press. 